\title{
Actual issues of assessment and regulation of surface water quality
}

\author{
Eugeny Venitsianov ${ }^{1 *}$, Georgy Adzhienko ${ }^{1}$, Sergey Yasinsky $^{2}$, and Mariya Kozlova ${ }^{1}$ \\ ${ }^{1}$ Institute of Water Problems of the Russian Academy of Sciences, Gubkina 3, 119333, Moscow, \\ Russia \\ ${ }^{2}$ Institute of Geography of the Russian Academy of Sciences, 29 Staromonetny lane, 119017, \\ Moscow, Russia
}

\begin{abstract}
The current state of surface water quality is stable, but it is characterized by a number of problems that collectively call into question the effectiveness of the current water management system in the country. Over a long period of time, the volume of pollutants entering the uncontrolled, mainly diffuse, runoff to water bodies determines the unsatisfactory quality of natural waters and the poor environmental condition of water bodies. This is a consequence of the imperfection of the current water management system.
\end{abstract}

\section{Introduction}

Among the urgent scientific and technological problems of the Russian water sector, the priority ones are the poor regulatory framework, the economic mechanism of water use as well as poor monitoring system and wastewater treatment technologies used on-sites. We are lagging behind in measures to limit diffuse flow of runoff from catchment and residential areas, waste disposal, water protection from xenobiotics (pharmaceuticals, household, agricultural and industrial chemicals, etc.) and a risk-based approach to management.

\section{Problems of water quality management}

Financial support. In comparable prices, the current expenditures for water protection and rational use in 2015 compared to 2005 amounted to $85-86 \%$. The amount of funding for the main strategic tool for managing the industry has been more than halved by the federal program "Development of the Water Economy of the Russian Federation in 20122020". Research and development is seriously underfunded: instead of the planned 2.04 billion rubles only 900 million rubles are currently allocated.

Investments in water protection and rational use of water resources from all sources of financing over the past 10 years have been at the level of 25-30 billion rubles. Meanwhile, the calculations show that under the scenario of "non-deterioration of water resources", an

\footnotetext{
* Corresponding author: eugeny.venitsianov@gmail.com
} 
amount of about 47 billion rubles is required annually and more than 70 billion to improve the condition [1].

Water quality management of water bodies. An urgent problem for Russia is the transition to the regulatory principle based on the best available technologies (BAT) for industries and households utilities. The transition to this principle is proclaimed by the Federal Law of July 21, 2014 No. 219-FZ. About 50 technological reference books on BAT were developed for individual industries. However, there is no clear procedure to combine the BAT system with the current system of standards for permissible discharges (VAT), and a system of payments for negative environmental impacts has not been developed. There is a risk of repeating the sad experience with the standards of permissible impacts (NII) on water bodies that were developed for the basins of all large rivers, but are not yet included in the system for regulating wastewater discharges.

A similar problem arose with the developed Schemes for the Integrated Use and Protection of Water Bodies, which were supposed to provide environmentally and economically sound programs of measures to improve the state of water resources. The Scheme concept, dating back to the 1980s, is outdated by the time when the Water Code was adopted. In most countries, the impact of wastewater discharges from enterprises (both existing and projected) is estimated using mathematical models. For example, in the USA Total Maximum Daily Load (TMDL) is calculated which is a standard indicator (the analogue in Russia is the Standard for harmful effects on water bodies), establishing a total daily maximum load on the portion of the water body or object as a whole [4]. In Russia, the calculation methods of the early 1950s are still used. There should appear computer information systems equipped with the models for water basins and their sections. The transition to digital management in the water sector will require dramatic changes in training for the industry.

Inefficiency of environmental supervision. Federal Service for Supervision of Natural Resources believes that its main task is to increase revenues to state budgets of the constituent entities of the Russian Federation for pollution of water bodies, and not to improve the ecological state of water bodies.

Imperfection of the monitoring and statistics systems. There are no methods for assessing uncontrolled (diffuse) runoff and secondary pollution from bottom sediments; it is not reliable to take into account the discharges of pollutants from point ones i.e. controlled sources, since the statistical forms of water management $(2 \mathrm{TP})$ are filled in by the enterprises themselves, and the reliability of the data is not verified.

The country does not have environmental monitoring of negative environmental impacts sources (even controlled). Given the current level of funding and the state of the technology base, the supervision system is not able to carry out such work.

The studies show that uncontrolled diffuse sources for many water bodies exceed the amount of pollution from controlled point sources, often 5-10 times. However, they are beyond the control.

Scientific and methodological base for natural waters quality management. In Russia, focusing on maximum permissible concentrations (MPC) indicators and integrated indices, is also outdated. It does not pay due attention to the physicochemical and hydrobiological processes of water quality formation, the interaction of the components of a water body - water mass, aquatic organisms, bottom sediments, coastal zone. The methodological and instrumentation base for water quality monitoring is also outdated.

Limited inventory of hazardous pollutants. Organic xenobiotics are not monitored, although in developed countries the number of determined xenobiotics has been actively growing since the beginning of the 1990s and the measures are being taken to regulate their entry into water objects. 
A characteristic feature of many xenobiotics is their high biological activity. Despite the low and ultra-low concentrations in water bodies, their impact on the inhabitants of water bodies and humans through the drinking water consumed is very significant.

In the lack of information on the real state of protected water bodies, very controversial documents appear. For example, one of them is the Order of the Government of the Russian Federation of July 8, 2015 No. 1316-r "List of pollutants for which state regulatory measures are applied in the field of environmental protection". The pollutant nomenclature does not include a number of dangerous organic xenobiotics. The term "state regulation measures" is not clarified.

Lack of pollutants monitoring. In what phase forms are the substances present in water at the micro level? This can be a dissolved phase, a solid mineral or organic phase, a colloidal organic phase and a planktonic phase in the water.

When a contaminant enters the water in a truly dissolved form, i.e. in the form of ions or molecules, the redistribution of the substance between the phases present in the water necessarily begins. Some of the molecules or ions of the polluting substance are sorbed in suspensions, absorbed by large organic molecules, or settle to the bottom together with suspended solids.

The effect of different phases on a living cell or on the whole organism is different. Truly dissolved substances (molecules or ions) pose the greatest danger, since they most easily penetrate the membrane of the cell. Those forms that are absorbed by other substances (suspensions, colloids by large molecules) are less dangerous. This property is not taken into account in the MPC standard.

Most suspended and colloidal particles have sorption properties. Therefore, suspended solids are not at all a passive part of water, but concentrators and carriers of most pollutants. It is important to know the concentration of not only their dissolved forms, but also the content in suspensions.

It is necessary to improve the monitoring system for petroleum products. After getting into water, oil ceases to exist as a mixture of components: various chemical, physicochemical, and metabolic transformations carried out by aquatic organisms occur with it. However, in Russia, the MPC value was developed only for petroleum products belonging to the hydrocarbon group $(\mathrm{HC})$ as a whole. It does not take into account the toxicity specific to all individual $\mathrm{HCs}$, the variability of the composition of the original oil, and the fact that oil as a mixture of HCs and HCs included in its composition are subject to transformations in the aquatic environment.

\section{Modern approaches to the assessment of organic xenobiotics danger}

A typical composition of municipal wastewater in large cities includes such groups of compounds as surfactants with anionic and cationic groups; anionic, cationic and nonionic surfactants; bleaching agents; paints and varnishes; emulsifiers; enzymes; musks and perfumes; preservatives; plasticizers; solvents; UV absorbents, pharmaceuticals, personal care products, persistent organic pollutants, etc. The total number of representatives of various groups of xenobiotics reaches 900-1000 representatives.

Chromatography and chromatography-mass spectrometry are currently effective methods of chemical analysis to identify organic xenobiotics. About $60 \%$ of chemical analyzes are performed by chromatographic methods. Using chromatography, it is possible to determine the content of supertoxicants, in particular dioxins, in environmental objects at extremely low concentrations of these substances. The main reason for success is the perfect equipment manufactured in developed countries. 
It is possible to identify any organic xenobiotics in water at concentrations of $10 \mathrm{ng} / \mathrm{dm}^{3}$, and in some cases up to $0.1 \mathrm{ng} / \mathrm{dm}^{3}$ with appropriate sample preparation and choosing the optimal method of identification. In this case, structural formulas are determined and on the basis of these data it is possible to evaluate the type of their dangerous action, and in some cases the limits of hazardous concentrations even in the absence of standardized MPC values for them.

In this case, calculation methods are used to assess the type of toxicity of the substance based on knowledge of the structure of the substance using information technology. A program is used to predict the biological activity of compounds according to their structure PASS (Prediction of Activity Spectra for Substances), which predicts 7157 activities based on data on 960 thousand compounds. The average prediction accuracy is $94.1 \%$ [6].

The methods based on the training sample also make it possible to predict some quantitative characteristics of toxicity. For example, the GUSAR program can calculate the acute toxicity index LD50 (average lethal concentration for tested organisms) and IGC50 (the concentration of half-maximum growth inhibition) [7].

Thus, an analysis of the quality of natural water requires an understanding of the multicomponent nature of pollution, an idea of the potential presence of synergism, and the need to identify the substances for which there are no formalized and normative methods.

\section{Water quality assessment and risk-based approach}

One of the most important tasks of monitoring systems should be the assessment of the environmental risk associated with the state of water bodies for the population, aquatic organisms and biota as a whole. Risk assessment should in turn stimulate the development of social activities related to anthropogenic impacts on natural waters (for example, environmental insurance and economic mechanisms for water management).

Russia has adopted an approach based on standardization of exposure using MPCs, which in world practice is called the concept of "zero" risk. Currently, in Russia there are two main systems of standards for the quality of surface waters - for water management permissible concentrations and fisheries permissible concentrations use of water bodies. Each of these systems establishes a single standard for all water bodies of the country, despite the huge difference in physical, geographical, climatic and socio-economic conditions.

Modern Russian business and municipal enterprises are neither technologically nor economically prepared to meet current high standards. The establishment of technologically unattainable, economically unjustified and environmentally unreasonable rigid standards leads, contrary to the intentions of the legislative bodies, not to improve the environmental situation, but to worsen it. A loophole appears in the form of temporarily allowed limits for discharges. The procedure for the appointment of these limits has not been established and allows arbitrariness and abuse.

In turn, in the environmental legislation of developed countries, in particular in the European Union, for more than 20 years there has been a systematic transition to a riskbased approach [3]. For each of the pollutants, based on information about its properties, the probability of exposure to living organisms and the possible negative effects of such exposure are determined.

The risk-based approach to environmental regulation is different from the traditional approach. In developed countries, it is implemented through a number of systems:

- a system of requirements for permits on negative environmental impact for companies;

- $\quad$ a system of control activities for environmental authorities;

- a system for regulating the manufacturers market. 
Most of these systems are based on the REACH (Registration, Evaluation and Authorization of Chemicals) approach used in the European Union [5].

The REACH system is aimed at controlling the circulation of chemicals and minimizing the harm from their use to human health and the environment. A fundamental approach to assessing the chemical safety of a substance includes three components [2]:

- hazard assessment - the collection and analysis of information on the physicochemical and biological properties of substances, methods of production and use, and environmental effects;

- impact assessment - determining the degree of exposure of substances to humans and environment at all stages of substance life cycle, taking into account all methods of its production and use;

- risk profile - a comparison of the substance exposure level with safe threshold values for humans and environment.

One of the main REACH requirements is to assign manufacturers and suppliers responsibility for assessing the risks and dangers of chemicals. According to REACH, they are required to conduct a risk assessment for chemicals supplied to the markets to ensure its safety for human health and the environment.

Assessing the substance level of exposure to natural creatures is the basis for assessing environmental risk and is calculated as the ratio of the predicted environmental concentration (PEC) of a substance in a water body based on models to the predicted no effect concentration (PNEC) of a substance in water.

Currently, more than 100 thousand chemicals are in circulation in the European Union, of which more than 520 chemicals are banned or significantly limited in access to the market. Since the introduction of REACH, the production of hazardous substances decreased by $11.5 \%$ (19 million tons), in particular, the production of substances representing a serious danger decreased by $10 \%$ (5 million tons) [8].

According to various estimates, the implementation of REACH cost manufacturers of the European Union $€ 2-7$ billion. At the same time, the total economic benefit from the introduction of REACH, according to various estimates, is $€$ 6.9-34.4 billion per year [8].

\section{Conclusion}

The water management system in the Russian Federation needs a significant reform of the main system elements. The revision of approaches to the management for water basins, regulatory for negative impact on water bodies, conducting control and supervisory activities, monitoring an expanded list of hazardous substances in water, as well as the monitoring methods themselves, is a priority for such development. The development of the scientific foundations of this activity is the most important task of hydrology and related sciences about water resources and their management.

The work was carried out within the framework of the topic no. 0147-2019-0004 (state registration no. AAAA-A19-119040990079-3) Of the state task of the IWP RAS and with the financial support of the Russian Foundation for basic research, project no. 19-05-50082 "Diffuse transfer of pollutants by micro particles from the territory of a large city to the water bodies of the Volga basin (for example, Nizhny Novgorod)". 


\section{Reference}

1. The concept of the Federal target program "Development of the water sector of the Russian Federation in 2012-2020" was Approved by a Government decree Of the Russian Federation of July 28, 2011 N 1316-p

2. Dara L. A Strategic approach to risk based regulation by the EPA, Ireland, from: http://risksummit.eu/wp-content/uploads/2013/03/risk-based-regulation-by-the-epaireland_dara-lynott.pdf.

3. General Report 2015. European Chemicals Agency, Helsinki, March 2016.

4. Guidance for Water Quality-Based Decisions: The TMDL Process. - US Environmental Protection Agency (EPA). Washington, DC Doc. No. EPA 440 / 4-91001. April 1991.

5. Risk and Regulatory Policy: Improving the Governance of Risk by OECD Reviews of Regulatory Reform, 2010, from: http://regulatoryreform.com/wpcontent/uploads/2015/02/oecd-risk-and-regulatory-policy -2010.pdf (Accessed 15 March, 2020)

6. Filimonov D.A., Poroikov V.V. Probabilistic approach in activity prediction // Chemoinformatics Approaches to Virtual Screening. Cambridge (UK): RSC Publishing, 2008. - p. 182-216.

7. Lagunin A. QSAR Modelling of Rat Acute Toxicity on the Basis of PASS Prediction / A. Lagunin, A. Zakharov, D. Filimonov, V. Poroikov // Molecular informatics, 2011. 30. - p. 241-250.

8. https://publications.europa.eu/en/publication-detail/-/publication/07ad8b92-dbca-11e7a506-01aa75ed71a1/language-en/format-PDF (Accessed 15 March, 2020) 